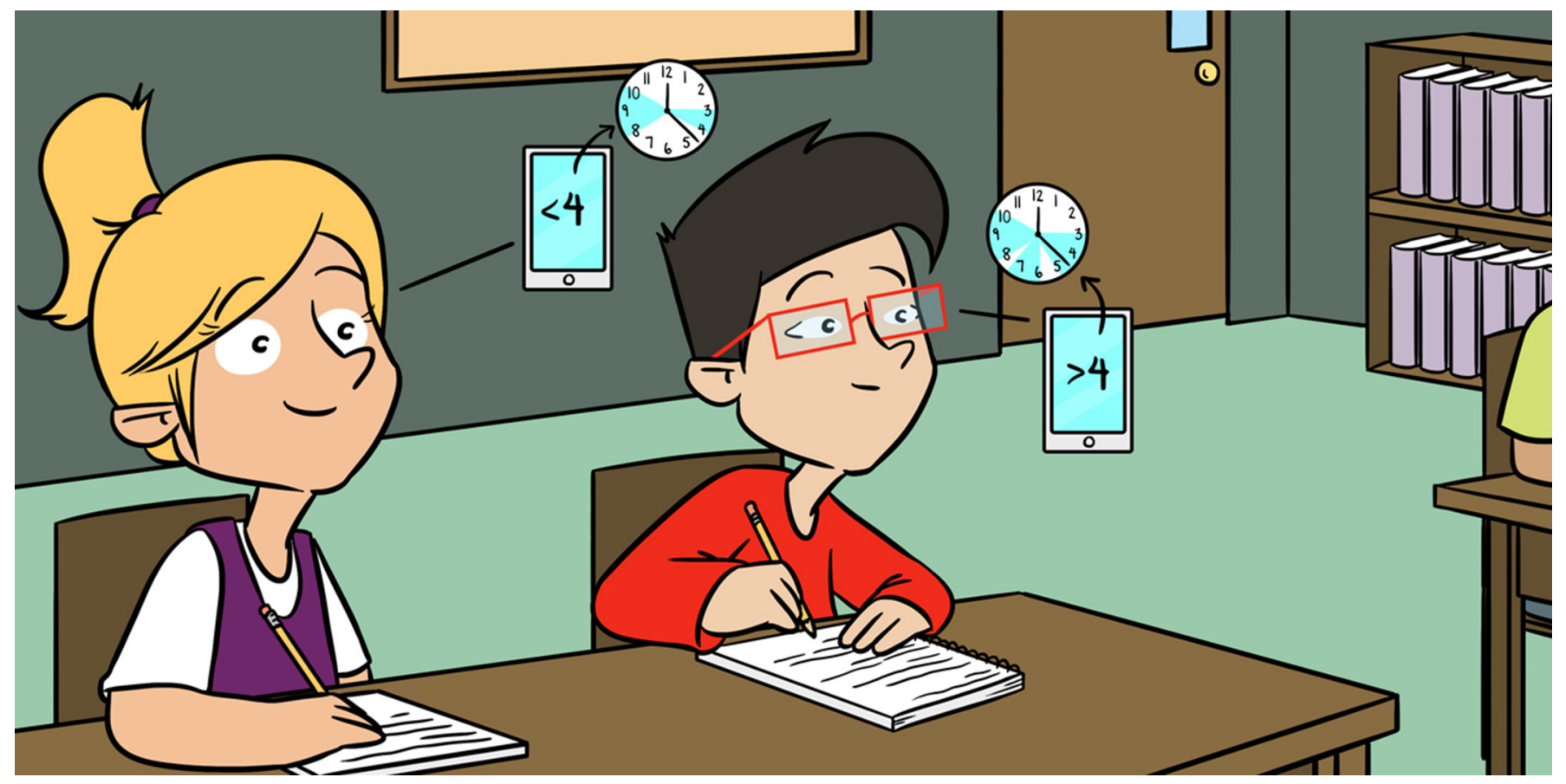

\title{
DO SMARTPHONES HURT OUR EYES BY CAUSING SHORTSIGHTEDNESS?
}

\section{Saoirse McCrann ${ }^{1 *}$, James Loughman ${ }^{1}$, John S. Butler ${ }^{1,2}$ and Daniel lan Flitcroft ${ }^{1,3}$}

${ }^{1}$ Centre for Eye Research Ireland, School of Physics, Clinical and Optometric Sciences, Technological University Dublin, Dublin, Ireland

${ }^{2}$ School of Mathematical Sciences, Technological University Dublin, Dublin, Ireland

${ }^{3}$ Children's University Hospital, Dublin, Ireland

\section{YOUNG REVIEWERS:}

JESSICA

AGE: 12

LIA

AGE: 12
Shortsightedness is caused by the eye growing too long, which results in faraway objects, such as the board in school, appearing blurry. People who are shortsighted wear glasses or contact lenses to see better. But would not it be incredible to figure out and avoid whatever causes shortsightedness, so we could wave goodbye to our never-clean, always-lost, forever-slipping-down-our-face glasses? Well, scientists have already started to solve the puzzle of shortsightedness and have discovered that time spent doing close-up tasks, such as reading, may put us at risk of shortsightedness. But now there is another near task we must consider, our ground-breaking, picture-taking, TikTok-making smartphones! We therefore carried out the first ever study looking at shortsightedness and smartphone data use and discovered that young people growing up with smartphones appear to be at greater risk of shortsightedness. 
SHORTSIGHTEDNESS

Occurs when the eyes grow too long, causing distant objects to appear blurry.

\section{RETINA}

The inner surface of the back of the eyeball, which converts light into signals that are sent to the brain for visual recognition.

\section{WHAT IS SHORTSIGHTEDNESS?}

In the same way that we grow taller, our eyes also grow until we reach a certain age. However, different parts of our eyes can grow in different ways. This can sometimes cause our eyes to grow too long, causing a condition known as shortsightedness [1]. If you are shortsighted, this means that far away objects, like the board in school, appear blurred (Figure 1). In a normal eye that has grown just the right amount, light will focus perfectly on the back of the eye, which is known as the retina, and a clear image will be formed. However, if the eye grows too long, the light going through it will be out of focus when it reaches the retina, which means a blurry image will be seen. To correct for blurry vision, people who are shortsighted wear glasses or contact lenses to bring the light into focus at the retina, so they can see a clear image. People who are extremely shortsighted may need operations on their eyes and medicines when they are older, because their eyes are in danger from being too stretched [2].

It is important to know that although glasses help shortsighted people to see better, they are not a cure for shortsightedness. Once an eye grows too long it cannot be reversed. Blurry vision is a symptom of shortsightedness, and glasses only deal with this symptom by helping people to see more clearly. This is like taking an anti-allergy tablet for itchy eyes or a runny nose when you have an allergy to cats. The best thing to do if you are allergic to cats is to avoid them in the first place! So, could we also do this for shortsightedness? Could we figure out and avoid whatever causes shortsightedness and prevent blurry vision symptoms? Could we wave goodbye to our never-clean, always-lost, forever-slipping-down-our-face glasses? Would not that be incredible?! Well, let us figure out what causes shortsightedness.

\section{NOBODY LIKES AN UNSOLVED PUZZLE!}

Scientists have been working hard to solve the puzzle of shortsightedness for many years. Finding out what causes shortsightedness is the first piece of the puzzle. We now know we may be shortsighted because it has been passed onto us from our parents, so thanks Mom and Dad [3]! However, the huge recent increase in the number of people with shortsightedness is caused by our lifestyle. We now spend less time outdoors, more time doing close work, such as reading, more time in school, and there are more people than ever living in cities [3]. All these factors have been linked to shortsightedness.

As time spent doing close-up tasks is one of the factors leading to shortsightedness, there is now another task we must consider. Can you guess what it could be? It is something we hold up close to see and touch. A small object that many people cannot spend a day 
Figure 1

(A) In a normal eye, the light is focused correctly on the retina. (B) In a longer, shortsighted eye, the light focuses in front of the retina, making far away objects appear blurry. (C) When a shortsighted eye is corrected with glasses, the lenses refocus the light onto the retina, so distant objects appear clear again.
A

NORMAL EYE

- Light is focused correctly on the retina at the back of the eye

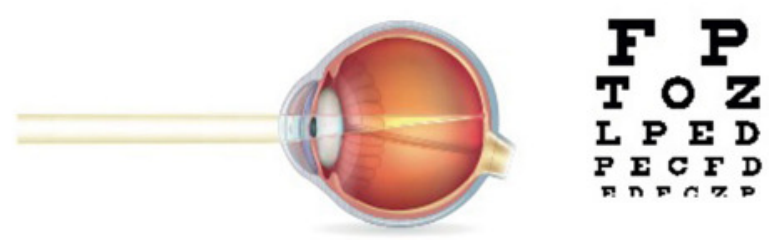

B

SHORTSIGHTED EYE

- The eye is too long and light is focused on front of the retina - Faraway objects are blurry

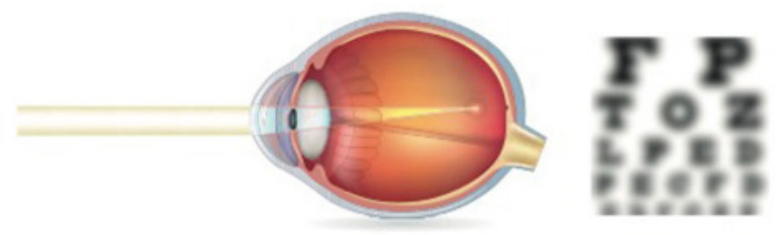

C

SHORTSIGHTED EYE WITH GLASSES

-The glasses lens has refocused light onto the retina

-The eye is still too long

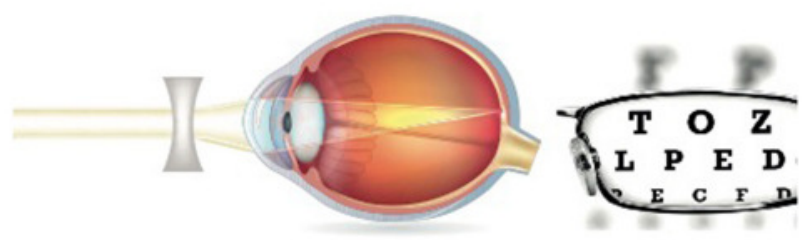

Figure 1

without. Yes, you guessed it! Our ground-breaking, picture-taking, TikTok-making smartphones! Could all the time we spend looking at our smartphones up close cause more shortsightedness? We decided to find out.

\section{ARE OUR SMALL SCREENS CAUSING OUR EYES TO GROW LONGER?}

We carried out the first-ever study looking at shortsightedness and smartphone data use [4]. We assessed smartphone use by looking at data usage, which can be found in the settings on any smartphone. We use smartphone data all the time: when we are looking at our phones to watch videos on YouTube, to play games, or to use social media apps like TikTok or Snapchat.

In our study, we asked students from primary schools (kindergarten to grade 6), secondary schools (grade 7-12), and universities to fill out a questionnaire about their smartphone data usage. We also asked them to track the amount of time they spent on their smartphones every day. By asking for both the students' smartphone data usage and the time spent on their smartphones, we obtained more reliable results, because time spent using smartphones can often be underestimated. Smartphone data is usually tracked over a long period of time, so we could use the data students reported to determine the average amount of data used on a typical day. We also asked students about when they use their smartphones and for what purposes. An eye 


\section{Figure 2}

How smartphone use may contribute to shortsightedness.

\section{OPTOMETRIST}

A person whose job is to conduct eye examinations for glasses and contact lenses, as well as to examine people's eye health.

\section{PERIPHERAL}

\section{DEFOCUS}

The phenomenon that causes images on the sides to be out of focus when we focus on an object straight ahead.

\section{SMARTPHONE USE AND MYOPIA}

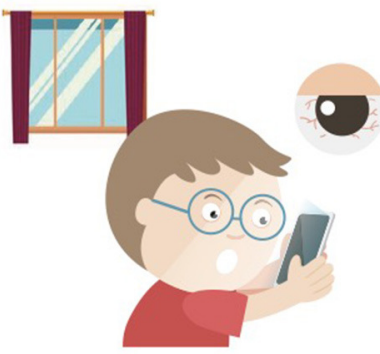

- Increased screen time / near work

Less time spent outdoors

Phones held near the face

Increased peripheral defocus on retina

Figure 2

specialist called an optometrist then checked if students wore glasses for shortsightedness.

We found that, on average, students spent over $4 \mathrm{~h}$ per day on their smartphones, which is more than one quarter of the time we spend awake every day. We also found that shortsighted students used a lot more smartphone data and spent more time on their phones compared to students who did not need glasses. Almost all students had smartphones, and older students used their smartphones more than younger students. Smartphones were mainly used for Snapchat, Instagram, and Facebook, which all require the use of our eyes.

\section{THE NITTY GRITTY SCIENCE}

So, how could our smartphones possibly be linked to shortsightedness? Well, our eyes, just like a camera, change their focus to see an object clearly. If we focus on a nearby object, such as a smartphone, objects in the distance are automatically blurred. You can try this at home by looking at your finger as you hold it close to your face. As you continue to focus on your finger up close, note that everything around it is blurred, including the words on this page.

This is called peripheral defocus [1]. Scientists believe that peripheral defocus plays a role in causing the eyes to grow longer when we spend a lot of time doing close-up work, therefore causing us to become more shortsighted (Figure 2).

\section{SMARTPHONES-ANOTHER PIECE OF THE SHORTSIGHTED PUZZLE}

One thing is crystal clear-smartphones are not going anywhere. The world is in love with smartphones and we use them a lot. However, the results of our study suggest there might be a downside: young people growing up in the era of the smartphone might be at greater risk of shortsightedness. This is worrying, as we rely on our eyes so 
much, from the moment we wake up until the moment we close them to go to sleep. We do not want to put our eyes at risk! What is more, smartphones can take away from time spent playing outside, and outdoor activities are good for our eyes. This is because daylight can help with eye growth and function and, when we are outdoors, we are often not doing close-up activities that can cause shortsightedness [2]. Therefore, putting our phones down and going outside into nature can really help to give our eyes the exercise and stimulus they need to grow normally.

\section{SO, ALL YOU HAVE TO DO IS BECOME A SUPERHERO!}

It is estimated half the world's population will be short-sighted by the year 2050 unless we do something about it. This is worrying, as, although shortsightedness can be corrected with glasses or contact lenses, it cannot be easily cured. Now that you know that spending too much time on our smartphones may contribute to shortsightedness, you can take steps to protect your eyes and the eyes of those you care about. You have the superpowers to be a scientist superhero. Your arch nemesis is shortsightedness. Your mission is to save yourself and the people in this universe from needing glasses. As part of your mission, you must use your superhuman strength to fight the urge to pick up your smartphone, join forces with the outdoor world, and protect your eyesight and eye health!

\section{ORIGINAL SOURCE ARTICLE}

McCrann, S., Loughman, J., Butler, J. S., Paudel, N., and Flitcroft, D. I. 2021. Smartphone use as a possible risk factor for myopia. Clin. Exp. Optom. 104:35-41. doi: 10.1111/cxo.13092

\section{REFERENCES}

1. Flitcroft, D. I. 2014. Emmetropisation and the aetiology of refractive errors. Eye (Lond). 28:169-79. doi: 10.1038/eye.2013.276

2. Flitcroft, D. I. 2012. The complex interactions of retinal, optical and environmental factors in myopia aetiology. Prog. Retin. Eye Res. 31:622-60. doi: 10.1016/j.preteyeres.2012.06.004

3. Morgan, I. G., French, A. N., Ashby, R. S., Guo, X., Ding, X., He, M., et al. 2018. The epidemics of myopia: aetiology and prevention. Prog. Retin. Eye Res. 62:134-49. doi: 10.1016/j.preteyeres.2017.09.004

4. McCrann, S., Loughman, J., Butler, J. S., Paudel, N., and Flitcroft, D. I. 2021. Smartphone use as a possible risk factor for myopia. Clin. Exp. Optom. 104:35-41. doi: 10.1111/cxo.13092

SUBMITTED: 05 June 2020; ACCEPTED: 11 March 2021; PUBLISHED ONLINE: 07 April 2021. 
EDITED BY: Tansy C. Hammarton, University of Glasgow, United Kingdom

CITATION: McCrann S, Loughman J, Butler JS and Flitcroft DI (2021) Do Smartphones Hurt Our Eyes by Causing Shortsightedness? Front. Young Minds 9:569850. doi: 10.3389/frym.2021.569850

CONFLICT OF INTEREST: The authors declare that the research was conducted in the absence of any commercial or financial relationships that could be construed as a potential conflict of interest.

COPYRIGHT () 2021 McCrann, Loughman, Butler and Flitcroft. This is an open-access article distributed under the terms of the Creative Commons Attribution License (CC BY). The use, distribution or reproduction in other forums is permitted, provided the original author(s) and the copyright owner(s) are credited and that the original publication in this journal is cited, in accordance with accepted academic practice. No use, distribution or reproduction is permitted which does not comply with these terms.

\section{YOUNG REVIEWERS}

\section{JESSICA, AGE: 12}

I love Harry Potter and Star Wars. My favorite subjects are physics and art.

\section{LIA, AGE: 12}

Lia has just entered secondary school and enjoys art and music. She plays cello for an orchestra and is learning the piano. During COVID lockdown, Lia has become very keen on binge series viewing on Netflix.

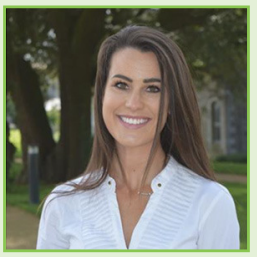

\section{AUTHORS}

\section{SAOIRSE MCCRANN}

I wrote this article as a post-doctoral researcher and clinical trial investigator at the Centre for Eye Research in Technological University Dublin, where I was researching new ways to slow down the progression of shortsightedness in children. I have previously worked on exciting clinical trials aiming to slow down the progression of shortsightedness in children using an eye drop. I have also carried out studies investigating smartphone use and shortsightedness, as well as exploring parents' attitudes toward shortsightedness and their awareness of this condition. I currently work on exciting eye-related projects that can improve and extend people's lives, in a global healthcare company called Novartis. *mccrannsaoirse@agmail.com

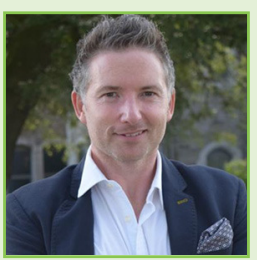

\section{JAMES LOUGHMAN}

I am a Professor of Optometry and Vision Science focused on preventing eye disease, especially in children. I am the founder and Director of the Centre for Eye Research Ireland (CERI), a research facility at Technological University Dublin 


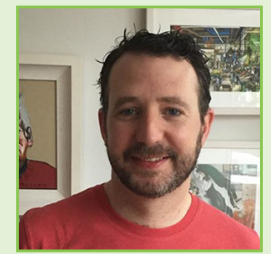

established to develop new solutions for preventing blindness through clinical trials and other research. My research interests include the prevention and treatment of common causes of blindness, such as shortsightedness, glaucoma, age-related macular degeneration, and diabetes. I also work on big data analysis, which means finding new ways to analyse really big data sets that are too large to figure out using normal software.

\section{JOHN S. BUTLER}

I am a Mathematics Lecturer in the Technological University Dublin, Ireland. I use my dual backgrounds in mathematics and neuroscience to understand the world using mathematics. I have researched how we use vision, touch, hearing, and body motion for walking, driving, and flying. I have used giant robots to fly people through virtual reality. When not teaching or researching, I like to play with my 6 year old daughter.

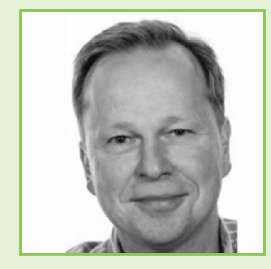

\section{DANIEL IAN FLITCROFT}

I am a consultant pediatric ophthalmologist principally based at the Children's University Hospital, Dublin, Ireland. I am also an associate Clinical Professor of Ophthalmology in University College Dublin and Adjunct Professor of Vision Science in Technological University Dublin. My primary research interest is in eye growth and the development of shortsightedness in children. I am the author of several books including a graphic children's novel entitled The Time Travelers Guide to Life, the Universe and Everything, which takes a journey through space and time on a beam of light with the ultimate travel guide: Albert Einstein! 